\title{
The emergence of the idea of a 'restorative city' and its link to restorative justice
}

\author{
Grazia Mannozzi*
}

\section{Introduction}

From the very beginning, mainly criminologists, criminal lawyers and social workers have processed and fostered the theory of restorative justice. The basic, simple, yet revolutionary idea behind it is to encourage dialogue with cooperative and constructive processes, in order to manage conflict by listening and acknowledging the other person's dignity and by a concrete, credible offer of monetary or even symbolic reparation.

From a practical viewpoint, restorative justice has been interpreted with various forms of methods and standard procedures: these mainly include mediation, conferencing, restorative dialogue and circles. The common thread linking the different methodologies is the dialogue form of the meeting, the perspective of reparation and the fundamental role of the mediator/facilitator, appointed as an impartial, equidistant, adequately trained individual. ${ }^{1}$ In concrete terms, restorative justice was initially used with young offenders, as a diversion intervention, and subsequently with adults for even serious offences and during the administration of the sentence.

Although it began as an approach to conflict arising from an offence, restorative justice has shown over time to be extremely adaptable. Restorative methods have spilled beyond the sphere of extra-judicial settlements to be experimented in various fields and not merely in a reactive, but also in a proactive dimension (i.e. with a view to preventing conflict): from family conflict to interethnic or interreligious conflicts; from school bullying to improper or oppressive behaviour on university campuses; from inappropriate conduct or mobbing in the workplace, to the management of disputes in complex organisations. Of particular interest among these areas of intervention is the emergence of the so-called restorative cities.

* Grazia Mannozzi is professor of Criminal Law and of Restorative Justice at the University of Insubria, Como, Italy.

Contact author: grazia.mannozzi@uninsubria.it.

1 See ECOSOC Resolution 2002/12 Basic principles on the use of restorative justice programmes in criminal matters; Directive 29/2012/EU of the European Parliament and of the Council of 25 October 2012 establishing minimum standards on the rights, support and protection of victims of crime, and replacing Council Framework Decision 2001/220/JHA; Council of Europe Recommendation $\mathrm{CM} /$ rec 2018(8) concerning restorative justice in criminal matters. 
In the contexts mentioned above, it is better to speak of restorative practice or of a restorative approach rather than of restorative justice. The terminological clarification reflects the essence of the phenomenon: in these contexts, methods of restorative justice need to be adapted to the characteristics and players in the conflict to be handled or prevented. Contrary to what occurs when managing a conflict having a criminal relevance, which resorts to victim-offender mediation or family group conferencing, a formal conference is often unnecessary and more versatile instruments are sufficient, such as restorative circles, or even more informal methods of intervention, while continuing to pay close attention to the restorative nature, already detected in the terminology used.

The development of restorative justice easily explains how the use of culture and restorative methods is a challenge, which makes us query how we run schools, businesses and public administration (Mannozzi \& Lodigiani, 2015), how we manage youth policies and intervene in underprivileged districts or those prone to criminality. Opening up to a restorative culture also means setting prevention and intervention procedures at the community level (Shearing \& Wood, 2003) for situations of unrest or conflict in social, scholastic, community or in public and private professional contexts, which gradually may increase the recourse to the essential components of the restorative justice approach, such as listening, dialogue, making amends, promoting responsibility, cooperation and reparation (Liebmann, 2007).

\section{The beginning}

The creation of restorative cities was a direct consequence of the theoreticalapplicative development of restorative justice (Van Ness, 2010), which began from circumscribed, sectorial experiences related to criminal offences (Walgrave, 2017: 107) to become an affirmed, formally acknowledged methodology with supranational guarantees.

To promote a restorative city is a challenge: there are no available standards or guidelines to follow. There are some extremely interesting, local experiences to look at bearing in mind however, that every urban structure requires an intervention tailor-made to its own requirements, needs and features. The first to start were the cities of Hull and Leeds, in England (Mirsky, 2009). Others followed in various European countries.

It is not necessarily the cities with the greatest socioeconomic problems, social injustice issues, which take the restorative approach. The use of the latter depends on the sensitivity of the individuals working in strategic sectors to start up restorative city projects: they could be school managers, university lecturers, representatives from the social services and from the non-profit sector and magistrates. Much depends on the ability of these individuals to meet and dialogue.

The true challenge is to take the methods and practices of restorative justice into key sectors for the town's rebirth: schools, districts, municipal administration, associations providing non-profit services, judicial services. This challenge is 
not without the need to find funding for a network-based project, which requires adequate time to design and implement.

The design of a restorative city implies that the partners, who intend to begin such a necessarily network-based project, share a series of essential elements in order to:

1 Identify the key values of restorative justice to detect the main inspiration behind the interventions to be implemented;

2 Be aware of the linguistic challenge, which implies the need to promote and encourage the ability to use, when necessary, a restorative language (careful, welcoming, non-judgemental, cooperative) in the various contexts where they intend to intervene;

3 Know the best practices already in use elsewhere to implement a restorative approach;

4 Raise awareness in the community of the meaning, the potential and the limits of restorative justice;

5 Enter into agreements and memoranda of intent with institutions and organisations operating within the territory;

6 Identify gate-keepers capable of intercepting conflict and understanding its extent;

7 Be able to create practical routes for a restorative management of conflict;

8 Understand the need to rely on adequately trained, qualified mediators/facilitators;

9 Take the opportunity to scientifically supervise the project in synergy with institutions and universities.

The methods of restorative justice can be applied to urban contexts, despite the fact that each context could feature different levels of interindividual and social conflict, not necessarily arising from poverty, unrest and deprivation.

The experiences gained also in the first restorative cities (Mirsky, 2009) indicate it is possible to achieve interesting results not only in terms of conflicts reduction, with related improvement in the quality of social, work and school relationships (and a subsequent rise in student learning performance) (Llewellyn \& Parker, 2018: 409), but also with regard to the social reintegration of deviant or marginal individuals.

It is certainly not easy to change urban, school or welfare micro-systems from within, by challenging inveterate standard practices, often rooted in procedures that privilege the punitive, interventionist approach, in order to process less coercive, inclusive, restorative and responsive answers (Burford, 2018) to unlawful, undesired behaviour or to destructive or simply adverse events. 
However, in the words of Francis Bacon: "in rebus quibuscumque difficiliorubus non expectandum, ut quis simul, et serat, et metat, sen preparatione opus est ut per gradus maturescant". ${ }^{2}$

\section{Restorative cities: a work in progress}

The following pages present the experience of six restorative cities - Brighton (UK), Bristol (UK), Leuven (Belgium), Como (Italy), Tempio Pausiana (Italy), Whanganui (New Zeland) - to offer to the scientific community an overview of some projects that are currently in progress. In addition to those that are described in the following text, there are obviously other, consolidated or recently established experiences of restorative cities worldwide that are worthy of attention.

The choice of the six cities to be presented here was born from a bottom-up path, which has its roots from several meetings in a perfect restorative style. First, reference must be made to the international conference of the European Forum for Restorative Justice in Tirana in June 2018, which offered an opportunity for discussion and dialogue between representatives of several restorative city initiatives. In January 2019, an international seminar dedicated specifically to restorative cities was held at the University of Insubria, at Como, which has an ongoing project to become a restorative city (see this issue, p. 309). On that occasion, the idea of setting up a working group within the European Forum for Restorative Justice specifically on restorative cities was developed. ${ }^{3}$ Once established, the working group then chose to communicate the experiences discussed during the seminar to a wider audience, through this journal.

The presentation of the experiences is set according to a frame divided into five sections: origins of the project; theoretical and conceptual basis; operationalisation; ongoing processes and, finally, findings and challenges. The Notes from the Field is then concluded by some final observations and remarks from Christopher Straker.

\section{References}

Braithwaite, J., Burford, G. \& Braithwaite, V. (2019). Learning from the human services. How to build better restorative justice and responsive regulation. In G. Burford, J. Braithwaite \& V. Braithwaite (eds.), Restorative and responsive human services (pp. 210-233). New York: Routledge.

2 F. Bacon, Sermones Fideles sive interiora Rerum, No. XLV, for the English version see F. Bacon, Essays, Civil and Moral. The Harvard Classics, 1909-1914: 'In all negotiations of difficulty, a man may not look to sow and reap at once; but must prepare business, and so ripen it by degrees'. It should be noted that the English translation has used the term 'negotiation' which is different form the Latin rerum (things).

3 EFRJ Working Group on Restorative Cities: www.euforumrj.org/about-the-forum/workinggroup-restorative-cities/. 
Burford, G. (2018). Keeping complexity alive: restorative and responsive approaches to culture changes. The International Journal of Restorative Justice, 1(3), 356-371. doi: 10.5553/ijrj/258908912018001003002.

Lambert, C., Johnstone, G., Green, S. \& Shipley, R. (2011). Building restorative relationships for the workplace. Goodwin Development Trust's journey with restorative approaches. A research report with recommendations for organisations seeking to implement Restorative Approaches. Retrieved from https://restorativejustice.org.uk/sites/default/files/ resources/files/Building\%20Restorative\%20Relationships\%20for\%20the \%20Workplace.pdf (last accessed 11 May 2019).

Liebmann, M. (2007). Restorative justice: how it works. London: Jessica Kingsley Publishers.

Llewellyn, K.R. \& Parker, C. (2018). Asking the 'who': a restorative purpose for education based on relational pedagogy and conflict dialogue. The International Journal of Restorative Justice, 1(3), 399-412. doi:10.5553/ijrj/258908912018001003005.

Mannozzi, G. \& Lodigiani, G.A. (eds.) (2015). Giustizia riparativa. Ricostruire legami, ricostruire persone. Bologna: il Mulino.

Mirsky, L. (2009). Hull, UK: toward a restorative city. Restorative practices EForum. Retrieved from www.iirp.edu/pdf/Hull.pdf (last accessed 11 May 2019).

Shearing, C. \& Wood, J. (2003). Nodal Governance, democracy, and the new 'Denizens'. Journal of Law and Society, 30(3), 400-419. doi:10.1111/1467-6478.00263.

Van Ness, D.W. (2010). RJ city: phase 1 final report. Centre for Justice \& Reconciliation Prison Fellowship International. Retrieved from restorativejustice.org/am-site/media/ rj-city-final-report.pdf (last accessed 11 May 2019).

Walgrave L. (2017). Restorative justice is not a panacea against all social evils. In I. Aertsen \& B. Pali (eds.), Critical restorative justice (pp. 95-110). Oxford: Hart Publishing. 